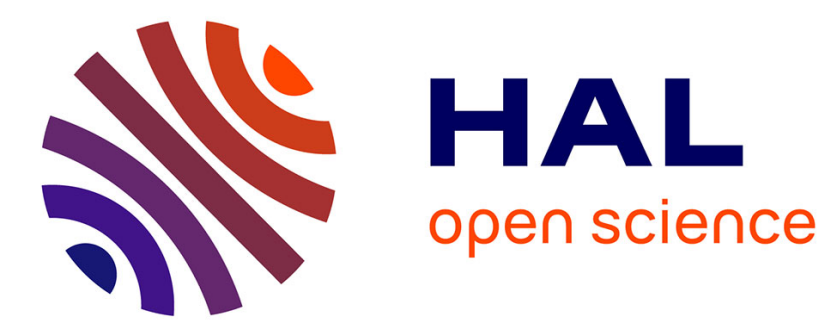

\title{
Performance of a Diesel Particle Filter Damaged by Drilling Holes in the Filter Walls to Simulate Internal Micro-cracks
}

Denis Bemer, Dominique Thomas, Stéphanie Pacault

\section{To cite this version:}

Denis Bemer, Dominique Thomas, Stéphanie Pacault. Performance of a Diesel Particle Filter Damaged by Drilling Holes in the Filter Walls to Simulate Internal Micro-cracks. Emission Control Science and Technology, 2020, 6 (4), pp.442-449. 10.1007/s40825-020-00172-0 . hal-03021970

\section{HAL Id: hal-03021970 https://hal.science/hal-03021970}

Submitted on 24 Nov 2020

HAL is a multi-disciplinary open access archive for the deposit and dissemination of scientific research documents, whether they are published or not. The documents may come from teaching and research institutions in France or abroad, or from public or private research centers.
L'archive ouverte pluridisciplinaire HAL, est destinée au dépôt et à la diffusion de documents scientifiques de niveau recherche, publiés ou non, émanant des établissements d'enseignement et de recherche français ou étrangers, des laboratoires publics ou privés. 


\section{Emission Control Science and Technology \\ Performance of a diesel particle filter damaged by drilling holes in the filter walls to simulate internal micro-cracks. --Manuscript Draft--}

\begin{tabular}{|c|c|}
\hline Manuscript Number: & ECST-D-20-00014R1 \\
\hline Full Title: & $\begin{array}{l}\text { Performance of a diesel particle filter damaged by drilling holes in the filter walls to } \\
\text { simulate internal micro-cracks. }\end{array}$ \\
\hline \multicolumn{2}{|l|}{ Funding Information: } \\
\hline \multirow[t]{3}{*}{ Order of Authors: } & Denis Bémer, Ph D \\
\hline & Dominique Thomas, Professor \\
\hline & stéphanie Pacault \\
\hline
\end{tabular}

Corresponding Author Secondary

Information:

Corresponding Author's Institution:

Institut National de Recherche et de Securite

Corresponding Author's Secondary Institution:

First Author:

Denis Bémer, Ph D

First Author Secondary Information:

Order of Authors Secondary Information:

Author Comments:

Response to Reviewers:

First of all, thanks for these pertinent remarks, which have been taken into account as far as possible.

The title has been modified in order not to introduce confusion between DPF failures and the micro holes we made for the study.

Reviewer 1

The comments have been taken into account and integrated into the document. Concerning the other points we bring the following clarifications:

- You're right, the SV of the filters are lower than the current value of $30 \mathrm{~s}-1$ that you mention, but according to our simulations this will not have a significant effect on the downstream particle concentration. The increase in SV may also amplify the change in pressure drop but not significantly.

- We have chosen to use granular bed models to describe the filtration through a SiC porous substrate. Reference [13] is therefore well suited.

Figure 11. SiC filter material: Electron microscope photograph of channel surface. From https://dieselnet.com/tech/dpf_wall-flow.php.

Fig.A1 : Measurements were carried out on various construction machines of all ages 
and types operating on a construction site in the Paris region in 2018. All DPF were retrofitted. We do not have more details about these machines and the DPF.

- "low idle speed or high idle speed" : Idling tests on construction machines were carried out 10 minutes after receipt of the machine, as the machine had previously been running (hot engine).

Reviewer 3

The term "solid" particle has been added although it is not accurate (the particles are mostly liquid), but it is true that it is a normative reference.

Clarifications have been made regarding the emission limit established from the solid particles number concentration and the occupational exposure limit value based on the mass concentration of elemental carbon (estimated from BC).

BC - solid particles : No, indeed, the number concentration of solid particles is not directly comparable to the mass concentration of $\mathrm{BC}$. These two concentrations were measured only because they are involved in the emission limit values (number concentration) and in the workplace air (EC/BC concentration).

- Flow resistance curve (Fig.5): As mentioned in the document the difference in DP between the new filter and the drilled filter is of same order of magnitude as the uncertainty. So the ratio DP (new filter) / DP drilled filter is not useful.

- Indeed, the fractures that can occur within a DPF can be quite different from the simple channel drilling we have done. We just want to evaluate the impact that a microleak can have on the filter performance. It is true that this approach may be far from reality, but not necessarily: see "Best practice guidelines diesel particle filters - VERT Association 2016 - www. VERT-certification.eu". In this document it is shown that the deterioration of the filter can be caused by the breaking of the channel closure plugs. All other proposed corrections and clarifications have been made to the document. 


\title{
Performance of a diesel particle filter damaged by drilling holes in the filter walls to simulate internal micro-cracks.
}

\author{
Denis Bémer ${ }^{1}$, Dominique Thomas ${ }^{2}$, Stéphanie Pacault ${ }^{1}$ \\ ${ }^{1}$ INRS, rue du Morvan 54519, Vandoeuvre, France \\ ${ }^{2}$ Université de Lorraine, CNRS, LRGP, F-54000, Nancy, France
}

\begin{abstract}
Diesel particle filter (DPF) is an effective way of reducing soot particles in the exhaust of diesel engines. The new emission regulations for non-road machineries effectively require that they are equipped with DPFs. However, these devices can be damaged and lead to an increase in the concentration at the filter outlet, which can exceed the emission limits. A study has been conducted to evaluate the impact of a micro-leak, created within a ceramic honeycomb filter, on its performance, i.e. filtration efficiency and pressure drop. The measurements carried out, as well as a modelling of the leak phenomenon, show that the simple measurement of the pressure drop is insufficient for the detection of these micro-leaks, which result in a significant drop in efficiency, all the more important as the flow resistance and efficiency of the filtering media is high.
\end{abstract}

\section{Introduction}

The IARC (International Agency for Research on Cancer) classified in 2012 diesel exhaust fumes as carcinogenic to humans (group 1) and the fine soot particles emitted by these engines are the main pollutants responsible for the toxicity of these fumes with nitrogen oxides [1,2]. Diesel Particulate Filters (DPFs) are a very effective means of reducing soot particulate emissions from diesel engine exhaust, especially from non-road mobile machineries, and limiting the concentration of particulate matter in the atmosphere, especially that of workplaces. However, DPFs can be damaged due to the high mechanical and thermal stresses they are subjected to [3], resulting in particulate emissions that may exceed the regulatory limit for non-road machinery. This limit is set at $10^{12}$ non-volatile (NV), "solid", particles, with a mobility diameter $\mathrm{d}_{\mathrm{m}}>23 \mathrm{~nm}, / \mathrm{kWh}$, i.e. about $2.10^{5}$ particles.cm ${ }^{-3}$ (European stage $\mathrm{V}$, 2017, [4]). Control of engine emissions is particularly important, as studies have shown that the $10 \%$ of the most polluting individual vehicle fleet contributes more than $85 \%$ of particulate emissions [5]. According to Burtscher [6], the periodic technical inspection (PTI) limit could be between $10^{5}$ and $10^{6} \mathrm{NV}$ particles. $\mathrm{cm}^{-3}$ at the emission of vehicles. Since deteriorated DPFs were one of the causes of abnormally high vehicle emissions, we investigated how micro-cracks in filter ceramics, simulated by drilling micro-holes in the channel plugs, which are difficult to detect by simply measuring pressure drop, could increase the particle concentration. Experimental studies have already been conducted, showing that small openings, less than $1 \%$ of the total channels, could indeed lead to particulate emissions exceeding the limits $[7,8]$. For this purpose, tests were conducted on two ceramic "honeycomb" filters (alternately open and closed channels at the inlet and outlet), from which channels were opened in order to simulate micro-cracks within the filter. Filtration efficiency and pressure drop as a function of leakage was modelled.

\section{$2 \quad$ Method}

The characteristics of the two silicon carbide filters (ceramic wall-flow monoliths), used for these tests, are given in Table 1. DPF 2 filter has a catalytic coating but not DPF 1 . The DPF 1 has a surface filtration almost ten times greater than that of the DPF 2, a flow resistance ten times greater, and also has a much higher filtration efficiency.

Table 1. Filter characteristics

\begin{tabular}{|c|c|c|}
\cline { 2 - 3 } \multicolumn{1}{c|}{} & DPF 1 & DPF 2 \\
\hline $\mathrm{N}$ & 6100 & 825 \\
\hline $\mathrm{D}(\mathrm{cm})$ & 22.0 & 12.8 \\
\hline $\begin{array}{c}\text { Cells density } \\
(\mathrm{cpsi})\end{array}$ & 205 & 83 \\
\hline $\mathrm{L}(\mathrm{cm})$ & 30 & 16 \\
\hline
\end{tabular}




\begin{tabular}{|c|c|c|}
\hline $\mathrm{a}(\mathrm{mm})$ & 1.5 & 2.0 \\
\hline $\mathrm{e}(\mathrm{mm})$ & 0.45 & 0.60 \\
\hline $\mathrm{V}_{\mathrm{b}}\left(\mathrm{cm}^{3}\right)$ & 3169 & 1003 \\
\hline $\begin{array}{c}\text { Pore size }(\mu \mathrm{m}) \\
(\text { manufacturer })\end{array}$ & $10-20$ & unknown \\
\hline $\mathrm{S}_{\mathrm{f}}\left(\mathrm{m}^{2}\right)$ & 10.4 & 1.05 \\
\hline $\mathrm{R}\left(\mathrm{m}^{-1}\right)$ & $1.15 .10^{10}$ & $9.1 .10^{8}$ \\
\hline $\mathrm{E}_{\min }(\%)$ & 99.8 & 80.0 \\
$\left(\mathrm{U}_{\mathrm{f}}=0.3 \mathrm{~cm} / \mathrm{s}\right)$ & $\left(\mathrm{U}_{\mathrm{f}}=1.4 \mathrm{~cm} / \mathrm{s}\right)$ \\
\hline
\end{tabular}

With N: the number of channels, D: the filter diameter, L and a: the length and width of a channel, respectively, e: the wall thickness between two channels, $S_{\mathrm{f}}$ : the surface filtration $\left(S_{\mathrm{f}}=\right.$ N.4.a.L $), V_{\mathrm{b}}$ : the filter bulk volume, R: the measured filter flow resistance (eq.3), $\mathrm{E}_{\min }$ : the minimum filtration efficiency measured at the filtration velocity $\mathrm{U}_{\mathrm{f}}\left(\mathrm{U}_{\mathrm{f}}=\right.$ airflow rate/ $\left.\mathrm{S}_{\mathrm{f}}\right)$.

\subsection{Measurements of initial characteristics (new filter)}

The initial filtration efficiency (new filter) and pressure drop were measured using the test bench described in the diagram in Fig.1. The initial filtration efficiency was determined from the number particle size distributions of a $\mathrm{NaCl}$ aerosol, measured with an SMPS analyzer $\left(\mathrm{Grimm}^{\circledR} 5400\right)$ upstream and downstream of the filter. The $\mathrm{NaCl}$ aerosol was generated by spraying a $1 \%$ by mass saline solution using a nebulizer (AkiMist ${ }^{\circledR}$ ) and introduced into a drying and mixing chamber (diameter $30 \mathrm{~cm}$ and length $1.2 \mathrm{~m}$ ). The upstream sample was diluted by a factor of 100 (VKL100, Palas ${ }^{\circledR}$ ), as well as the downstream sample from the DPF 2, whose concentration exceeded the SMPS limit. Three sequences of upstream/downstream measurements were carried out to determine the efficiency. The measurement uncertainty is established from these three sequences by means of a Student's test. The pressure drop of the DPF was measured for the different configurations tested: new filter and with drilled channels. The air flow rate is measured by means of a Venturi nozzle and by measuring the air velocity in the centre of the duct of diameter $\mathrm{D}=10 \mathrm{~cm}$, by thermal anemometry. 10 and 50 channels on DPF 1 have been drilled, and 5 and 20 channels on DPF 2. Figure 2 shows a view of the downstream surface of DPF 1 with the 10 drilled channels.

\subsection{Measurement from diesel particles}

A second installation was used to measure the diesel soot particulate matter concentrations upstream and downstream of the DPF, mounted at the exhaust of a diesel electric generator, whose power is varied according to the electrical resistances connected [9] (Fig.3). An analyser (TSI ${ }^{\circledR}$, NPET 3795) was used to determine the number concentration of non-volatile particles (NV), and an aethalometer (Aethlabs ${ }^{\circledR}$, AE51) was used to measure the mass concentration of black-carbon (BC) particles. The number concentration of NV particles is measured in order to situate the performance of the DPF in relation to the emission limit of $2.10^{5}$ particles.cm ${ }^{-3}$ while the mass concentration of $\mathrm{BC}$ is used to establish the performance in relation to the occupational exposure limit (OEL) at workplace of $50 \mu \mathrm{g} . \mathrm{m}^{-3}$, of elemental carbon EC [10] (BC is considered to be close to EC for diesel particles [11]).

An aerosol diffusion dryer, manufactured in the laboratory, was used for the downstream measurement with the aethalometer to remove water that could interfere with the measurement [12]. This dryer has been dimensioned to be adapted to the low sampling rate of the aethalometer $(100 \mathrm{ml} / \mathrm{min})$. Measurements upstream of the DPF were carried out after a thermo-dilution system (Testo ${ }^{\circledR}$, MD19) set at a temperature of $150{ }^{\circ} \mathrm{C}$, in order to hot dilute the aerosol and eliminate volatile compounds. No dilution was carried out downstream of the filter due to the too low particle concentration. The gas temperature upstream and downstream of the filter was controlled by means of thermocouples. The exhaust gas flow rate $\mathrm{Q}_{\mathrm{g}}$ was measured using the dilution bench into which the engine emission is injected without DPF (Fig.3). $Q_{g}$ is determined (eq.1) from the test bench dilution flow rate $\left(Q_{d}=845\right.$ $\left.\mathrm{m}^{3} / \mathrm{h}\right)$ and the concentrations in NV particles, measured by means of the NPET probe, at the engine exhaust $\left(\mathrm{Cn}_{\mathrm{e}}\right)$ and in the bench $\left(\mathrm{Cn}_{\mathrm{d}}\right)$ :

$$
Q_{g}=\frac{Q_{d} \cdot C n_{d}}{C n_{e}-C n_{d}}
$$


The measured gas flow rate was $64 \mathrm{~m}^{3} / \mathrm{h}$ at $3 \mathrm{~kW}$ electrical power and $52 \mathrm{~m}^{3} / \mathrm{h}$ at idle.

\subsection{Modelling pressure drop and filtration efficiency}

A model of filtration efficiency and pressure drop taking into account the leakage caused by the opened channels was carried out. It is based on the association of two flow resistances placed in parallel: one related to undrilled channels and the other, weaker, related to drilled channels. This imbalance in the values of the flow resistances will induce an imbalance in the flow rates through the open and undrilled channels for the same pressure drop. It is easy to show by calculating the flow resistance of open channels from Poiseuille's law that :

$$
\frac{\mathrm{Q}_{\mathrm{L}}}{\mathrm{Q}_{\mathrm{T}}}=\frac{1}{1+128\left(\frac{1-\beta}{\beta}\right) \frac{\mathrm{L}^{2}}{\mathrm{R}^{3}}}
$$

With:

$\mathrm{Q}_{\mathrm{L}}$ : the flow through the drilled channels $\left(\mathrm{m}^{3} / \mathrm{s}\right), \mathrm{Q}_{\mathrm{T}}$ : the total flow through the filter $\left(\mathrm{m}^{3} / \mathrm{s}\right)$.

$\beta=\mathrm{N}_{\mathrm{cp}} / \mathrm{N}$

$\mathrm{N}$ : total number of channels (-), $\mathrm{N}_{\mathrm{cp}}$ : number of drilled channels (-)

L: channel length $(\mathrm{m})$

a: channel width $(\mathrm{m})$

$\mathrm{R}$ : flow resistance of the new ceramic filter $\left(\mathrm{m}^{-1}\right)$

The flow resistance $\mathrm{R}$ is determined, in the absence of leakage, from the filter pressure drop given, in laminar regime, by the Darcy's law :

$$
\Delta \mathrm{P}=\mathrm{R} \mu \mathrm{U}_{\mathrm{f}}
$$

With $\mu$ : dynamic viscosity of the gas $(\mathrm{Pa} . \mathrm{s})$ and $\mathrm{U}_{\mathrm{f}}=\mathrm{Q}_{\mathrm{T}} / \mathrm{S}_{\mathrm{f}}$ : filtration velocity $\left(\mathrm{m} . \mathrm{s}^{-1}\right)$

A material balance on the perforated ceramic filter allows the expression of the pressure drop and filtration efficiency as a function of the leakage flow:

$\Delta \mathrm{P}=\mathrm{R}_{\mathrm{L}} \mu \mathrm{U}_{\mathrm{f}}$

with $\mathrm{R}_{\mathrm{L}}$ the resistance of the drilled filter given by :

$$
\mathrm{R}_{\mathrm{L}}=\mathrm{R} \cdot \frac{1-\frac{\mathrm{Q}_{\mathrm{L}}}{\mathrm{Q}_{\mathrm{T}}}}{1-\beta}
$$

The efficiency, obtained in the same way, is given by :

$$
\mathrm{E}=\mathrm{E}_{\mathrm{o}}\left(1-\frac{\mathrm{Q}_{\mathrm{L}}}{\mathrm{Q}_{\mathrm{T}}}\right)+\frac{\mathrm{Q}_{\mathrm{L}}}{\mathrm{Q}_{\mathrm{T}}} \mathrm{E}_{\mathrm{L}}
$$

With $\mathrm{E}_{0}$ : efficiency of the not altered ceramic filter at flow rate $\left(\mathrm{Q}_{\mathrm{T}^{-}} \mathrm{Q}_{\mathrm{L}}\right)$ and $\mathrm{E}_{\mathrm{L}}$ : collection efficiency of the drilled channel at $\mathrm{Q}_{\mathrm{L}}$ flow rate

The particle collection efficiency in open channels $E_{\mathrm{L}}$ can be neglected. One calculation shows that the penetrating fraction of a $0.1 \mu \mathrm{m}$ aerosol particle through an open channel is greater than $99 \%$ [13]. Equation 6 is then reduced to :

$$
E=E_{o}\left(1-\frac{Q_{L}}{Q_{T}}\right)
$$

Assuming $\mathrm{E}_{0}$ to be little different from the efficiency determined at the airflow rate $\mathrm{Q}_{\mathrm{T}}$, it is possible to determine the evolution of the efficiency as a function of the characteristics of the channels ( $L, a)$, the coefficient $\beta$ and the flow resistance of the undrilled filter.

\section{Results}


The fractional efficiency of DPF 1 and 2 in the initial state was determined respectively at flow rates $Q_{\text {T }}$ of 112 $\mathrm{m}^{3} / \mathrm{h}$ and $53 \mathrm{~m}^{3} / \mathrm{h}$ (Fig.4). The air velocities in the filter, characterized by the filtration velocity $U_{\mathrm{f}}$ and the space velocity $\mathrm{SV}=\mathrm{Q}_{\mathrm{T}} / \mathrm{V}_{\mathrm{b}}$, are given in Table 2 .

Table 2. Air velocities inside the filter

\begin{tabular}{|l|l|l|}
\hline $\mathrm{Q}_{\mathrm{T}}\left(\mathrm{m}^{3} / \mathrm{h}\right)$ & 112 & 53 \\
\hline $\mathrm{U}_{\mathrm{f}}(\mathrm{cm} / \mathrm{s})$ & 0.3 & 1.4 \\
\hline $\mathrm{SV}\left(\mathrm{s}^{-1}\right)$ & 9.8 & 14.7 \\
\hline
\end{tabular}

The efficiencies are very different, with efficiencies greater than $99.8 \%$ for DPF 1 and greater than $80 \%$ for DPF 2 , whose performance can be considered equivalent to that of a medium efficiency filter. The difference in filtration velocity does not explain the low efficiency of DPF 2 compared to DPF 1, which is well related to the nature of the filter material itself. This point was verified by testing the DPF 2 at a lower filtration velocity $\left(U_{\mathrm{f}}=0.7 \mathrm{~cm} / \mathrm{s}\right)$ which did not result in a significant change in efficiency.

Figure 5 shows the evolution of the pressure drop of the two filters as a function of the air flow rate for the different leakage configurations tested. The two filters were tested at different flow rates due to their very different filtration surfaces (Tab.1). The DPF 1 was tested between 90 and $220 \mathrm{~m} 3 / \mathrm{h}$, the DPF 2 between 50 and $120 \mathrm{~m} 3 / \mathrm{h}$, which corresponds to filtration velocities between $0.24-0.59 \mathrm{~cm} / \mathrm{s}$ and $1.3-3.2 \mathrm{~cm} / \mathrm{s}$ respectively.

The slope of the regression lines established for the new DPF 1 and 2 , are respectively $5.528 \mathrm{~Pa} /\left(\mathrm{m}^{3} / \mathrm{h}\right)$ and 4.372 $\mathrm{Pa} /\left(\mathrm{m}^{3} / \mathrm{h}\right)$. These values were used to determine the flow resistance $\mathrm{R}$ of the filters (eq.3) given in Tab.1. These tests show that, for a fraction of open channels $\beta$ of less than $1 \%$, the leak is difficult to detect by simply measuring the decrease in pressure drop compared to that of the new filter, as it is of the same order of magnitude as the measurement uncertainty $(10 \mathrm{~Pa}$ ). If a decrease is still detectable for the DPF 1 , with the highest flow resistance, no difference was observed in the case of the less resistant filter DPF 2.

These data were confirmed by calculating the pressure drop and particle concentration downstream of the filter as a function of leakage, as shown in Fig.6. At the rate $\beta=0.8 \%$, corresponding to the 50 holes of DPF 1 , the ratio of the downstream concentration to that found for the new filter $(\beta=0), \mathrm{rCn}_{\mathrm{s}}=\mathrm{Cn}_{\mathrm{s}}(\beta) / \mathrm{Cn}_{\mathrm{s}}(0)$, is 15 , for a variation of $\triangle \mathrm{P}$ equal to $10 \mathrm{~Pa}$. The equivalent calculation performed for the DPF 2 at the rate $\beta=2.4 \%$, corresponding to the drilling of 20 holes, gives an $\mathrm{rCn}_{\mathrm{s}}=1.21$ and a variation of $\Delta \mathrm{P}$ equal to $5 \mathrm{~Pa}$.

For both filters, the pressure drop variation established for the maximum leakage is very small and almost undetectable. On the other hand, with regard to the downstream concentration, the behaviours are much more marked for DPF 1, with a very significant increase in downstream concentration (by a factor of 15) and a very small increase for DPF 2 (by a factor of 1.2). The impact of a micro-leakage on the filtration efficiency will, therefore, be all the more important as the flow resistance of the media will be high. In general, filtration efficiency and flow resistance are correlated, so the degradation of filtration efficiency by micro-leakage will increase with the efficiency of the filter media. In other words, the more effective the filter, the greater the effect on the performance.

Indeed, considering that the flow resistance R can be evaluated from Kozeny-Carman's law [14] and the filtration efficiency $E_{d}$, considering only the diffusion filtration mechanism [15], we obtain these expressions only from parameters $\alpha$ and $d_{g}$ :

$$
\begin{aligned}
& \mathrm{R}=\mathrm{A} \cdot \frac{\alpha^{2}}{(1-\alpha)^{3} \cdot \mathrm{dg}_{\mathrm{g}}^{2}} \\
& \mathrm{E}_{\mathrm{d}}=1-\exp \left(\frac{-3 \alpha e \eta_{d}}{2 \mathrm{~d}_{\mathrm{g}}}\right)
\end{aligned}
$$


With $\eta_{d}$ the single filtration efficiency by Brownian diffusion: $\eta_{d}=\frac{B}{(1-\alpha) \cdot d_{g}^{2 / 3}}$

$\alpha$ : the packing density of the filter media, $\mathrm{d}_{\mathrm{g}}$ : the diameter of the constitutive $\mathrm{SiC}$ grains of the media, $\mathrm{A}$ and $\mathrm{B}$ terms independent of $\alpha$ and $d_{g}$.

It can be seen from these relations that $\mathrm{R}$ and $\mathrm{E}_{\mathrm{d}}$ increase with the packing density and as the grain diameter decreases. The only way to increase the efficiency of a media, without increasing its resistance, is through the action of electrostatic forces, which in this case play no role in the filter media.

The evolution of the downstream concentration as a function of the leakage rate $\beta$ was calculated from eq.7, in three filtration configurations, based on the geometrical characteristics of the DPF 1, but in varying the initial efficiency and resistance R (Fig.7). Calculations were made for an upstream concentration equal to that measured at the diesel engine emission i.e. $\mathrm{Cn}_{\mathrm{e}}=4.10^{7}$ particles. $\mathrm{cm}^{-3}$. As can be seen, the increase is very large at low leakage rates for filter $A$, the most efficient and resistant filter. A leakage rate of $\beta=0.75 \%$ is sufficient to reach the concentration of $10^{6}$ particles.cm ${ }^{-3}$, well above the emission limit set at $2.10^{5}$ particles. $\mathrm{cm}^{-3}$. For a leakage rate of more than $0.6 \%$, the concentration downstream of filter A becomes higher than that of filter B. On the other hand, the concentration downstream of filter $\mathrm{C}$, the least efficient filter, remains almost unchanged.

Measurements made on the "diesel" test bench confirm these modelling results. The measured and calculated number concentrations of NV diesel soot particles upstream and downstream of DPF 1 are shown in Fig. 8, as well as the mass concentration in BC. The increase in downstream concentration as a function of leakage is well highlighted. The experimental and theoretical data are in good agreement, although the model tends to underestimate the downstream concentration of the DPF with leakage. As can be seen, for the drilled filter, the particle number concentration and the BC mass concentrations exceed the respective limits of $2.10^{5}$ particles. $\mathrm{cm}^{-3}$ (emission) and $50 \mu \mathrm{g} \cdot \mathrm{m}^{-3}$ (occupational exposure limit).

For the maximum leakage studied ( 50 holes, $\beta=0.82 \%$ ) the concentration downstream of the DPF $\left(1.73 .10^{6}\right.$ particles. $\mathrm{cm}^{-3}$ ) is well above the emission limit set at about $2.10^{5}$ particles. $\mathrm{cm}^{-3}$. The corresponding concentration measured with the aethalometer (not shown), equal to $570 \mu \mathrm{g} \cdot \mathrm{m}^{-3}$ of BC is also higher than the occupational exposure limit value for diesel particles set at $50 \mu \mathrm{g} \cdot \mathrm{m}^{-3}$ of elemental carbon, (used in the absence of an emission limit for BC). It is clear that a small degradation of DPF is therefore likely to significantly increase the particulate matter concentration.

Figure 9 shows that the number concentration of NV particles (NPET analyser) and mass concentration of BC (aethalometer), measured downstream of the 10-holes drilled DPF 1, increase with engine power. This only results from the increase, by the same factor, of the upstream concentration, which goes from 7.5.106 $\mathrm{NV}$ particles. $\mathrm{cm}^{-3}$ at idle (downstream: $\approx 10^{5} \mathrm{NV}$ particles. $\mathrm{cm}^{-3}$ ) to $2.3 .10^{7} \mathrm{NV}$ particles.cm ${ }^{-3}$ for a power of $3 \mathrm{~kW}$ (downstream: 2.9.10 $0^{5} \mathrm{NV}$ particles. $\left.\mathrm{cm}^{-3}\right)$.

Kadijk et al. [16] measured emissions from test cycles (New European Driving Cycles, NEDC) and at low idle for a number of cars with different filter efficiencies. Concentration of NV particles $>23 \mathrm{~nm}$ with the engines warmed up were measured. The authors found that test cycle results correlate well with concentration measurements at low idle and then proposed to control vehicles only at idle. However, measuring only at idle could be a risk of minimizing the influence of micro-leakage in the DPF, which could only be revealed at higher engine operating speeds, as shown in Figure 9. In the absence of test cycles for NRMM, it is necessary to consider whether the idling measurement alone is sufficient. Measurements carried out in the field on non-road machineries show that the increase in particle concentration as a function of engine rotation speed is not systematic (Annex 1). In order to simplify the procedures for monitoring vehicle emissions, simple measurement at idle could therefore be enough. However, measurement under free acceleration, which is not more restrictive to implement in the field, would still be preferable because it would certainly be more penalizing, even if field measurements do not show a systematic increase in concentration with engine speed.

\section{Conclusions}


The study showed that leaks caused by micro-fractures/open channels in a DPF's ceramic, not detectable by simple measurement of the filter pressure drop, were indeed likely to significantly reduce filtration efficiency. Measurements and modelling clearly show that the impact of micro-leaks is all the more important as the media resistance to flow, and therefore its filtration efficiency, will be high. In other words, a high efficiency filter will have a greater degradation of performance due to micro-leakage than a low efficiency filter. This degradation of DPF performance can quickly lead to soot particle emissions exceeding emission limits and contamination of working atmospheres beyond the exposure limit values. These results confirm the need for a periodic monitoring of emissions for non-road machineries in the same way as for road vehicles, based on the measurement of the airborne particle concentration in the tail-pipe. The on-board diagnostic using PM sensors can also be a complement to periodic inspections.

\section{Annex 1}

Measurements of the number concentration of NV particles were carried out at the emission of construction machineries (loaders, excavators), working on two construction sites in the Paris region, all equipped with DPFs installed in retrofit, with the exception of one machine (Fig.A1). The measuring device consisted of a thermodilution system (MD19+ASET, Matter $\left.{ }^{\circledR}\right)$, set at temperatures of 150 and $300{ }^{\circ} \mathrm{C}$, and a measuring device for the number concentration $\left(<2.10^{6}\right.$ particles. $\left.\mathrm{cm}^{-3}\right)$ and the mean particle diameter $(10-300 \mathrm{~nm})$ DiscMini $($ Matter () . Measurements were carried out with the engine warm, at idle and under free accelerations. As can be seen, the results are highly contrasted. It can be noted that the filter of machine 8 was broken, as the concentrations are of the same order of magnitude as those of machine 3 without DPF $\left(>10^{7}\right.$ particles. $\left.\mathrm{cm}^{-3}\right)$. The filters on machines 5 and 6 were also defective, with concentrations of the order of $5.10^{6}$ particles.cm ${ }^{-3}$. The measurements clearly show differences between the concentrations established at idling and free acceleration, but not systematically. For machines 1, 7 and 8, the concentration measured under free acceleration is clearly higher than that established at idle, but no difference is observed for the others. It is therefore difficult to conclude on the increase in concentration with engine speed.

On behalf of all authors, the corresponding author states that there is no conflict of interest.

\section{References}

1. IARC monographs on the evaluation of carcinogenic risks to humans. (2012) Diesel and gasoline engines exhausts and some nitroarenes. World health organization, 105, Lyon.

2. Ilar, A., Plato, N., Lewné, M., Pershagen, G.: Occupational exposure to diesel motor exhaust and risk of lung cancer by histological subtype: a population-based case-control study in Swedish men. Eur. J. Epidemiol., 32(8), (2018).

3. Majewski, W.A. Diesel filter systems, https://dieselnet.com/tech/dpf_sys.php (2015).

4. European stage V for non-road emission standards - Regulation (EU) 2016/1628 (2017).

5. Gloor, B.: Investigation about functionality of DPF during PTI in Zürich. VERT® Forum 15.03.2018, https://www.vert-dpf.eu/j3/index.php/start-page/events/2-uncategorised/51-9th-vert-forum-vertfocus-event-1415-03-2018-zurich. (2018). Accessed 9 July 2019.

6. Burtscher, H., Lutz, Th., Mayer, A.: A new periodic technical inspection for particle emissions of vehicle. Emission Control Science and Technology, 5(3), 279-287 (2019).

7. Kasper, M., Mosimann, T.: Conformity of production testing for particle traps - A model experiment. $11^{\text {th }}$ ETH Combustion Generated Nanoparticles, Zürich (2007).

8. Yamada, H.: Emissions from HD trucks with damaged DPF and its detection at PTI. ETH Combustion Generated Nanoparticles, Zürich (2015). 
9. Bémer, D., Subra, I.: Monitoring particle emission for non-road diesel machineries equipped with particle filters. J. Aerosol Sci. 113, 153-165 (2017).

10. Directive (EU) 2019/130 of the European parliament and of the council of 16 January 2019.

11. Majewski W.A., Jääskelaïnen H., Exhaust Particulate Matter, https://dieselnet.com/tech/dpm.php (2019).

12. Cai, J., Yan, B., Ross, J. et al. : Validation of MicroAeth ${ }^{\circledR}$ as black carbon monitor for fixed-site measurement and optimization for personal exposure characterization. Aerosol and Air Quality Research, 14, 1-9 (2014).

13. Baron, P.A., Willeke K.: Aerosol measurement, J. Willey\&Sons, $2^{\text {nd }}$ ed. New-York (2001).

14. Majewski, W.A. Wall-flow monoliths, https://dieselnet.com/tech/dpf_wall-flow.php (2005).

15. Boulaud, D.: Use of granular beds in the inertial impaction regime for aerosol size distribution measurement. J. Aerosol Sci. 22, 273-287 (1991).

16. Kadijk, G., Elstgeest, M., Ligtering, NE et al.: Investigation into a periodic technical inspection (PTI) test method to check for presence and proper functioning of diesel particulate filters in light-duty diesel vehicles - part 2. Report TNO R10530 (2017). 


\section{Figures}

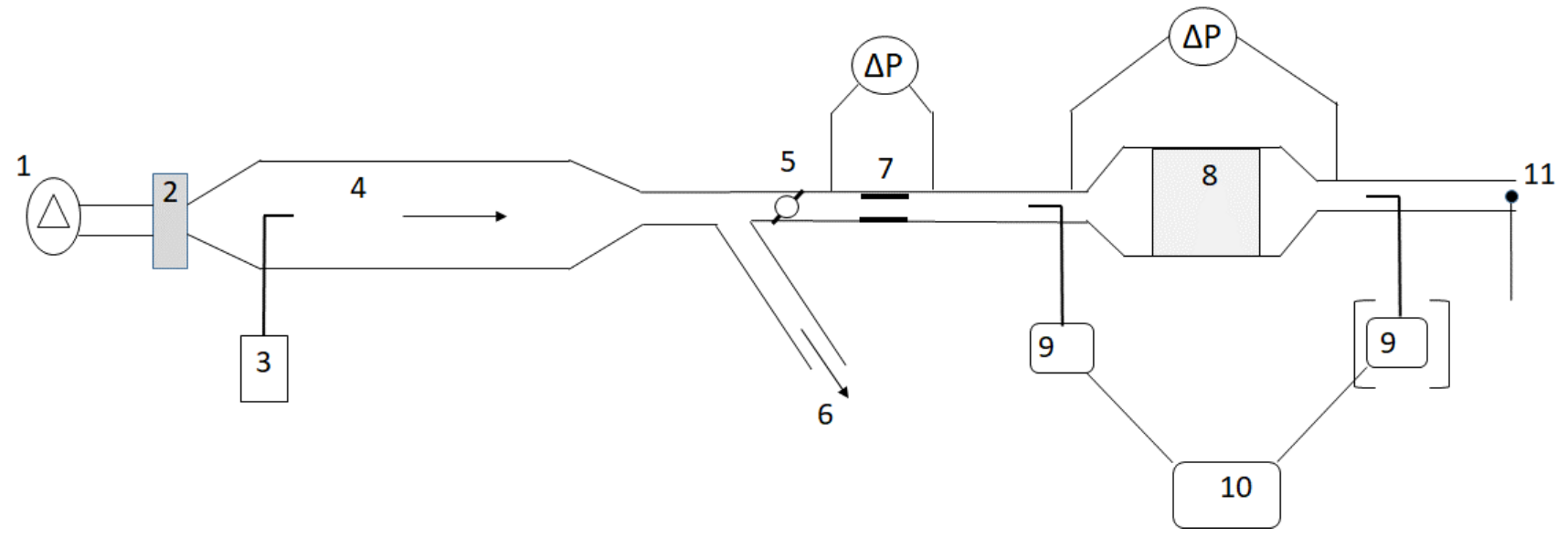

Fig.1 Schematic diagram for measuring filter efficiency and airflow - pressure drop characteristics. 1: fan, 2: HEPA filter, 3: $\mathrm{NaCl}$ aerosol generator, 4: drying and mixing chamber, 5: valve, 6: excess flow, 7: Venturi nozzle, 8: DPF, 9: dilutor VKL100, 10: SMPS, 11: thermal anemometer.

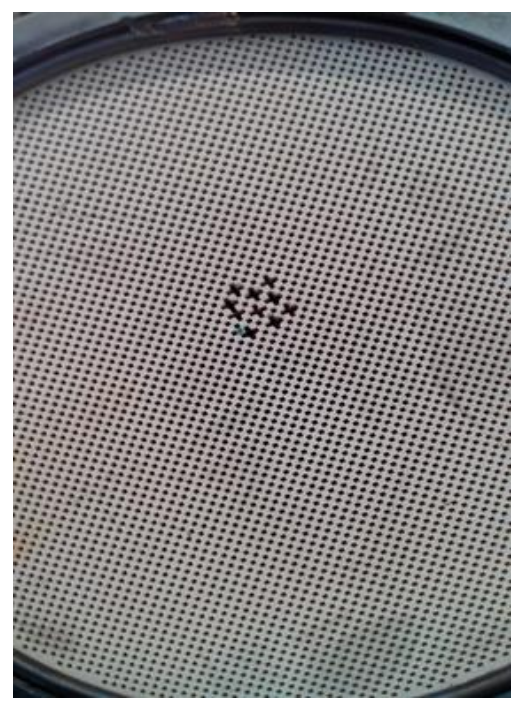

Fig.2 Downstream side of DPF 1 with 10 open channels. 


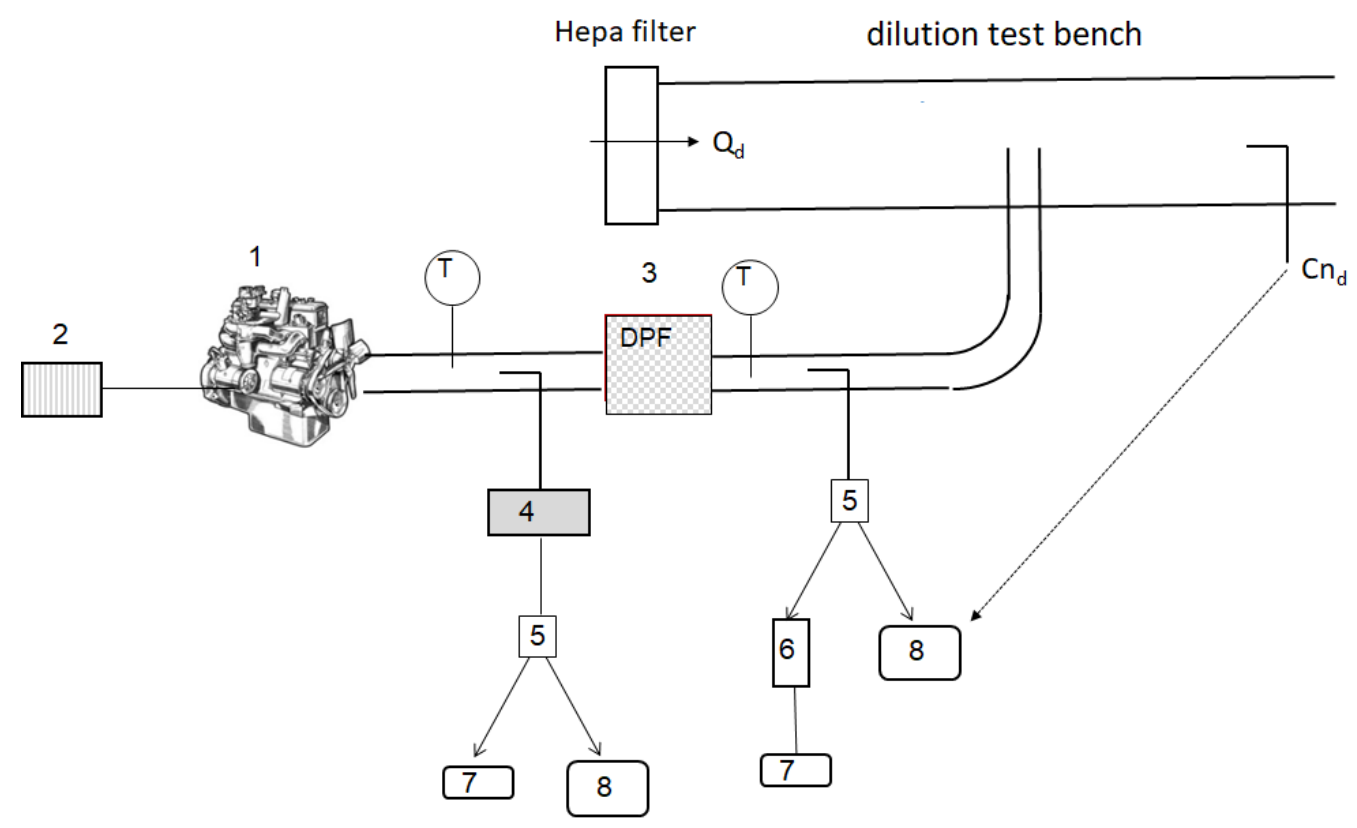

Fig.3 Schematic diagram for measuring diesel particulate matter concentrations upstream and downstream of the DPF. 1: diesel engine, 2: electrical resistors, 3: DPF, 4: MD19, 5: flow splitter, 6: dryer, 7: aethalometer, 8: NPET probe.

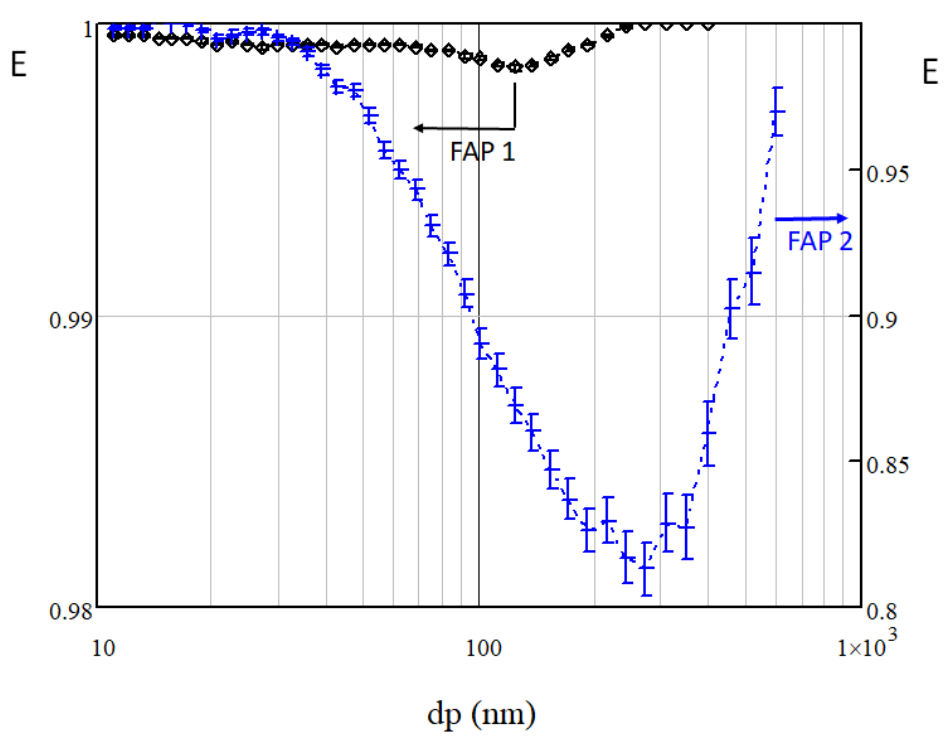

Fig.4 Fractional efficiency of DPF 1 and 2, measured at flow rates of 110 and $53 \mathrm{~m}^{3} / \mathrm{h}$ $\left(\mathrm{U}_{\mathrm{f}}=0.3\right.$ and $\left.1.4 \mathrm{~cm} / \mathrm{s}\right)$ respectively. 


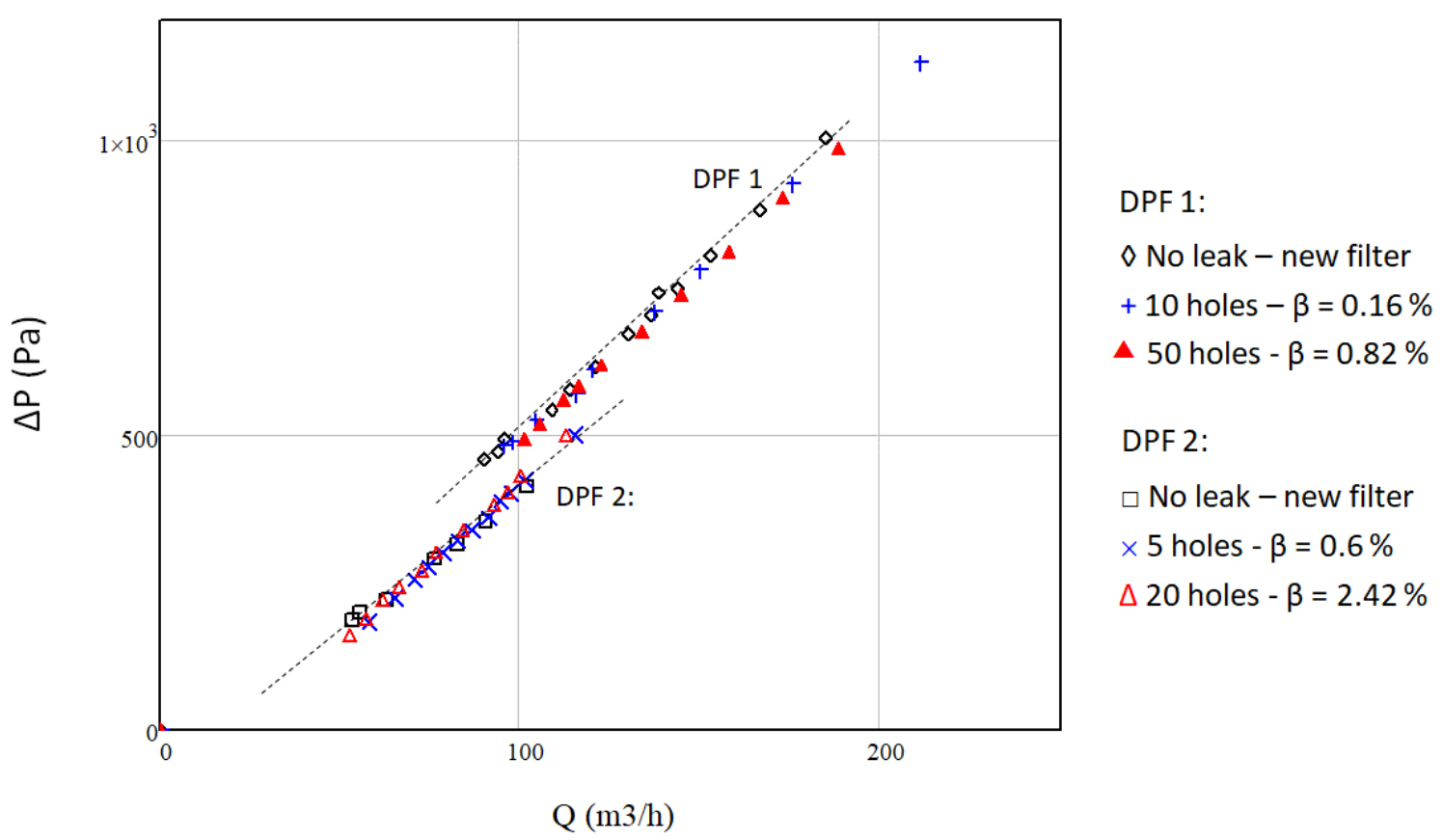

Fig.5 Measured variation $\Delta \mathrm{P}=\mathrm{f}(\mathrm{Q})$ of $\mathrm{DPF} 1$ and 2 as a function of the different leaks tested

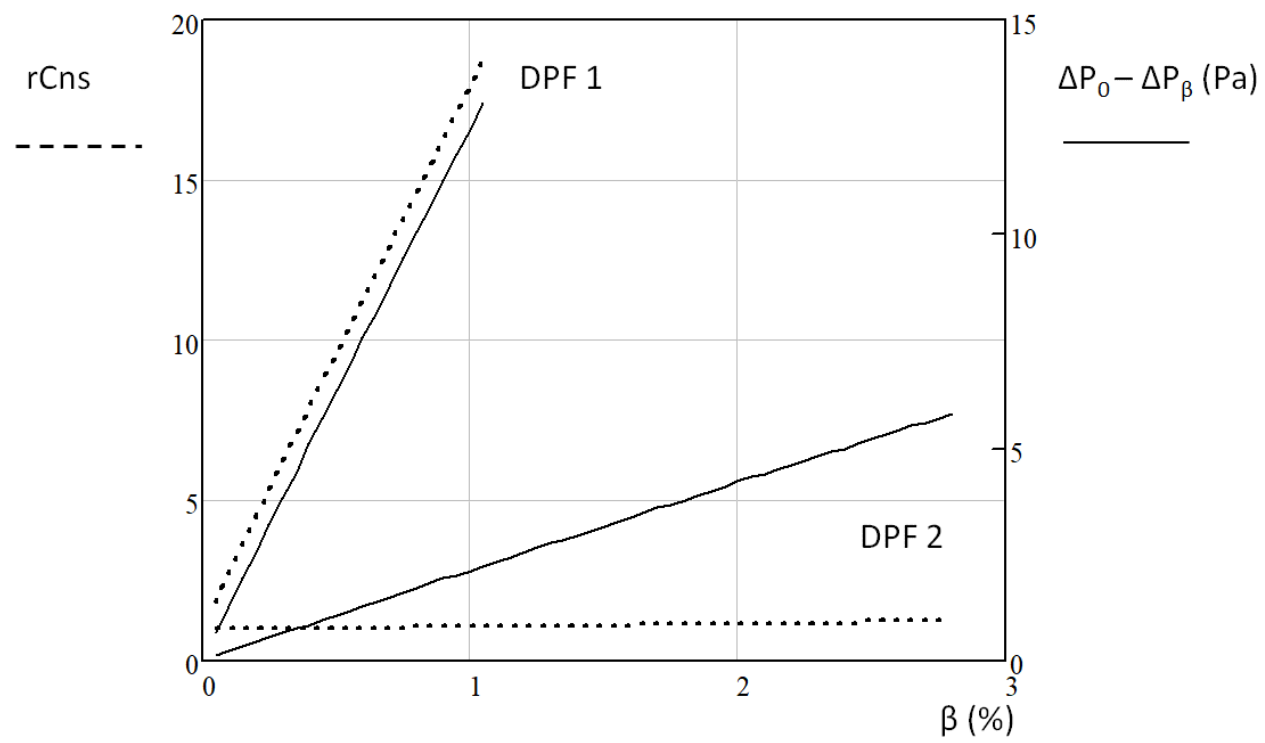

Fig.6. Calculated variation of the difference in pressure drop $(-)$ and ratio of downstream concentrations $\mathrm{rCn}_{\mathrm{s}}(. .$. as a function of leakage. $\Delta \mathrm{P}_{0}$ : pressure drop of new filter $(\beta=0), \Delta \mathrm{P}_{\beta}$ : pressure drop of the drilled filter at rate $\beta$, $\mathrm{rCn}_{\mathrm{s}}=\mathrm{Cn}_{\mathrm{s}}(\beta) / \mathrm{Cn}_{\mathrm{s}}(\beta=0)$. 


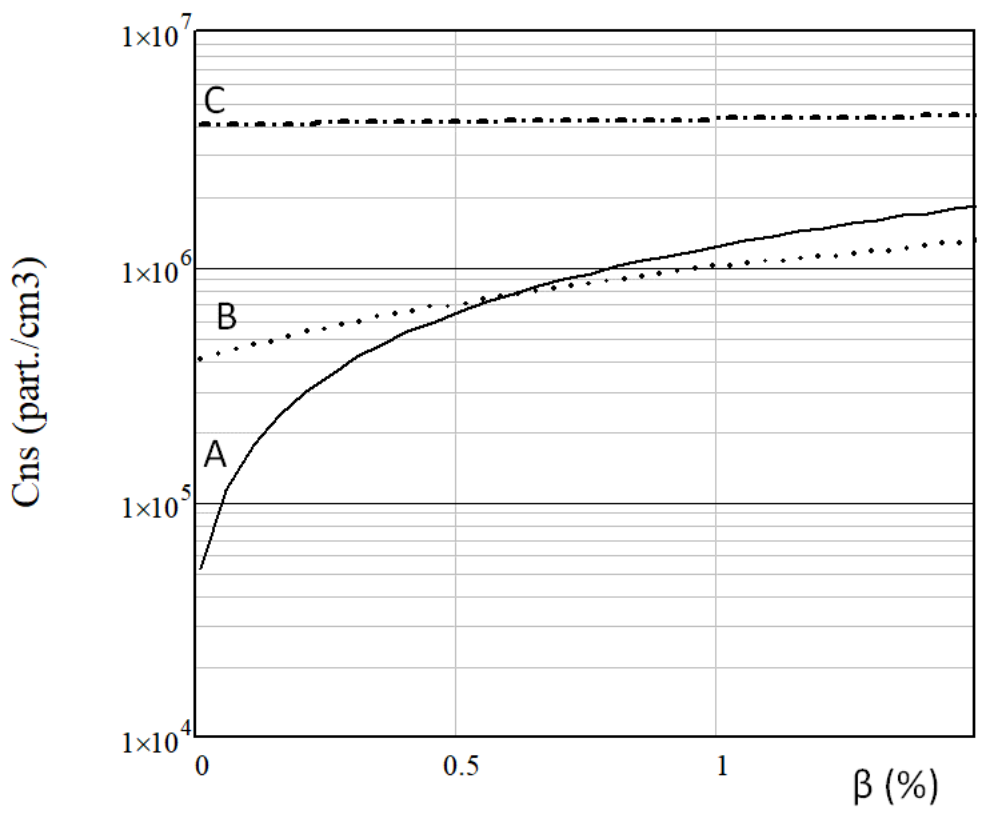

Fig.7 Calculation of the variation of downstream filter concentration $\left(\mathrm{Cn}_{\mathrm{s}}\right)$ as a function of leakage rate $\beta$ for cases: $\mathrm{A}\left(-, \mathrm{E}_{0}=99.9 \%, \mathrm{R}=10^{10} \mathrm{~m}^{-1}\right), \mathrm{B}\left(\ldots, \mathrm{E}_{0}=99.0 \%, \mathrm{R}=5.10^{9} \mathrm{~m}^{-1}\right)$ and $\mathrm{C}\left(-.-, \mathrm{E}_{0}=90.0 \%, \mathrm{R}=2.5 .10^{9} \mathrm{~m}^{-1}\right)$. Upstream concentration $\mathrm{Cn}_{\mathrm{e}}=4 \cdot 10^{7} \mathrm{part} / \mathrm{cm}^{3}$.

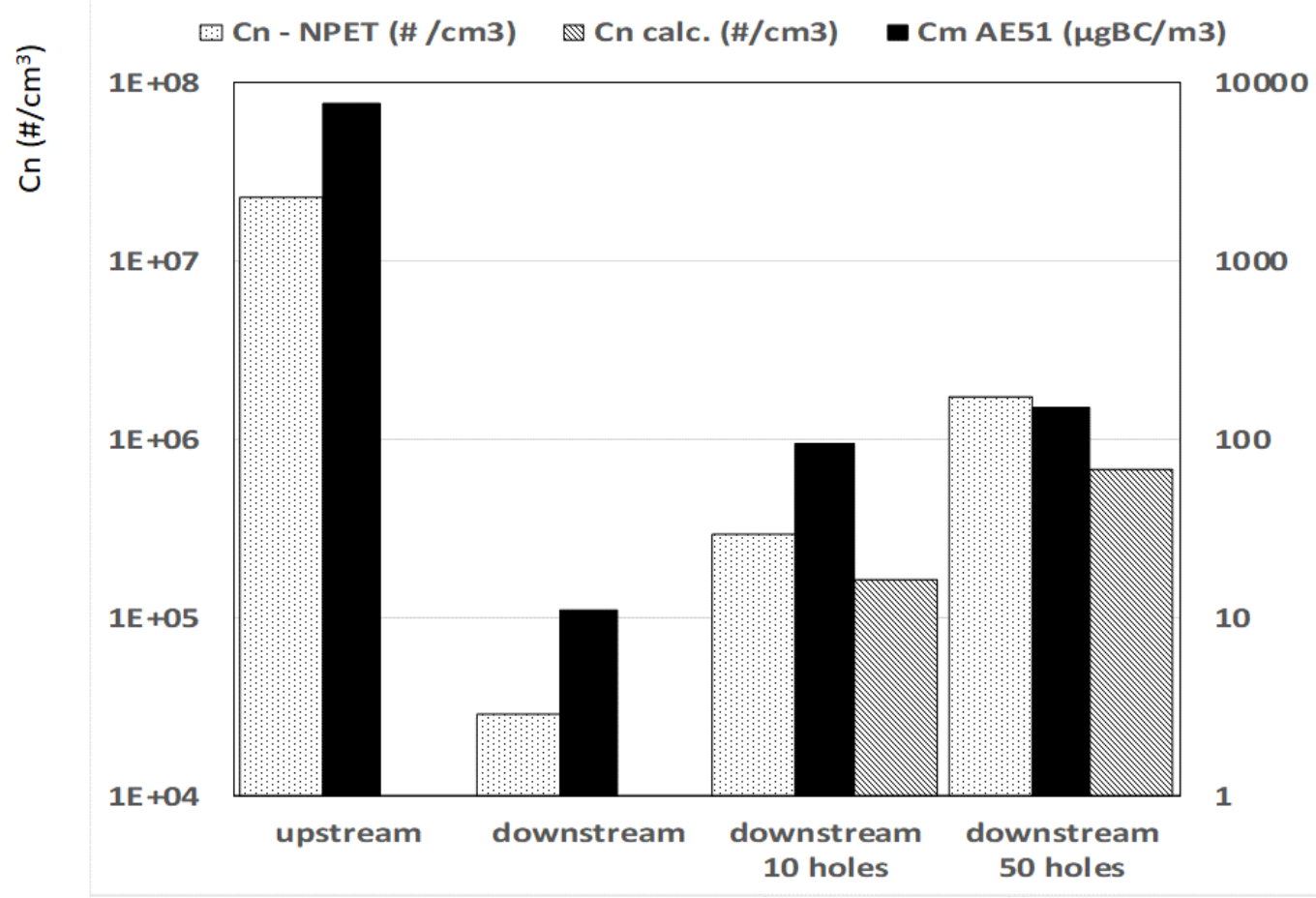

Fig.8 Number concentration of NV diesel particulate matter (Cn, experimental and calculated values), and mass concentration in BC (Cm $\square$ ), upstream and downstream of the new DPF 1, with 10 and 50 open channels. Engine speed corresponding to an electrical power of $3 \mathrm{~kW}$. 


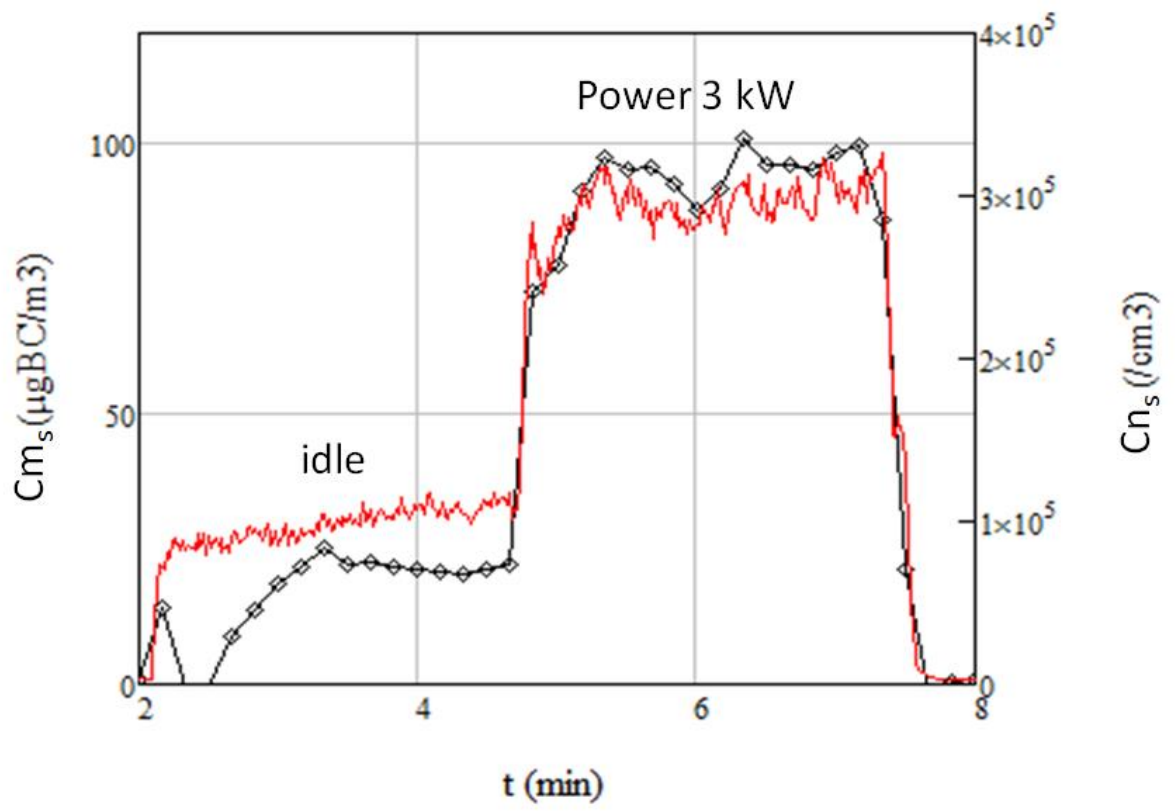

Fig.9 Number concentration of NV particles $\left(\mathrm{Cn}_{\mathrm{s}}-\right)$ and mass concentration of BC $\left(\mathrm{Cm}_{\mathrm{s}} \diamond\right)$ measured downstream of the 10-holes drilled DPF 1, at idle and for a power of $3 \mathrm{~kW}$.

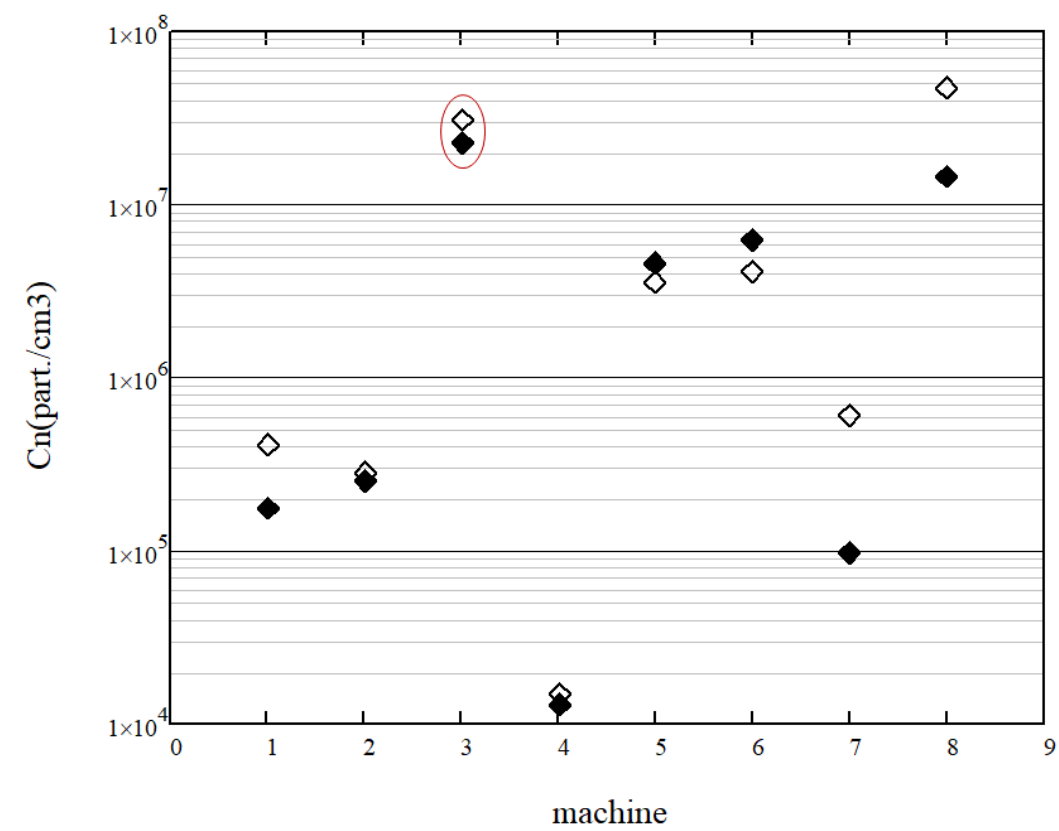

Fig.A1 Number concentration of NV particles at the emission of 8 machines, 7 of which are equipped with DPF, and one without DPF (machine 3). - : idle, $\diamond:$ free acceleration. 
